\title{
Chronic exposure to aluminum and melatonin through the diet: Neurobehavioral effects in a transgenic mouse model of Alzheimer disease
}

\author{
Celeste Di Paolo $^{\mathrm{a}, \mathrm{b}}$, Ingrid Reverte ${ }^{\mathrm{b}, \mathrm{c}}$, Maria Teresa Colomina ${ }^{\mathrm{b}, \mathrm{c}}$, José L. Domingo ${ }^{\mathrm{b}}$, Mercedes Gómez ${ }^{\mathrm{a}, \mathrm{b}, *}$ \\ ${ }^{a}$ Biochemistry and Biotechnology Unit, School of Medicine, IISPV, Universitat "Rovira i Virgili", Sant Llorenç 21, 43201 Reus, Catalonia, Spain \\ ${ }^{\mathrm{b}}$ Laboratory of Toxicology and Environmental Health, School of Medicine, IISPV, Universitat "Rovira $i$ Virgili", Sant Llorenç 21, 43201 Reus, Catalonia, Spain \\ ${ }^{\mathrm{C}}$ Research Center for Behavior Assessment (CRAMC), Psychobiology Unit, Universitat "Rovira i Virgili", 43007 Tarragona, Catalonia, Spain
}

\section{A R T I C L E I N F O}

\section{Article history:}

Received 11 December 2013

Accepted 11 April 2014

Available online 2 May 2014

\section{Keywords:}

Aluminum

Melatonin

Behavior

$\operatorname{Tg} 2576$

Alzheimer disease

\begin{abstract}
A B S T R A C T
Aluminum ( $\mathrm{Al}$ ) is a known neurotoxic element involved in the etiology of some serious neurodegenerative disorders such as Alzheimer disease (AD). Antioxidants like melatonin might protect neurons against the damage produced in AD. The APPSWE (Tg2576) transgenic mouse is one of the most used animal models developed to mimic AD damage. In the present study, wild type and Tg2576 mice were orally exposed during 14 months to Al, melatonin, and citric acid, as well as to all possible combinations between them. At 17 months of age, mice were evaluated for behavior using the open-field test and the Morris water maze. Transgenic animals exposed to melatonin only and to Al plus citric acid plus melatonin showed a good acquisition. No effects on acquisition in the Morris water maze were observed in wild type mice. With respect to the retention of the task, only melatonin wild type animals, and Al plus citric acid plus melatonin transgenic mice showed retention during the acquisition. Control wild type animals and Al plus citric acid plus melatonin transgenic mice showed good long term retention. Melatonin improved learning and spatial memory in Al-exposed transgenic mice.
\end{abstract}

(c) 2014 Elsevier Ltd. All rights reserved.

\section{Introduction}

Aluminum ( $\mathrm{Al}$ ) is a highly neurotoxic element without any known biological function. Human exposure to $\mathrm{Al}$ occurs primarily through contaminated food and water or airborne dust, as well as through antiperspirants, immunizations, allergy injections and antacids among others (Walton, 2012a, 2013; Yokel, 2000; Yumoto et al., 2009). Another possibility is occupational exposure. Thus, workers in the $\mathrm{Al}$ industry and miners are much vulnerable to $\mathrm{Al}$ exposure as a result of breathing dust containing $\mathrm{Al}$ (Percy et al., 2011). However, the most usual Al exposure for the general population is through the diet, mainly from dietary additives (Fekete et al., 2013; Walton, 2012a, 2013; WHO, 1989). The primary human dietary sources of $\mathrm{Al}$ in the US are foods and beverages. Coffee, wine, black and green tea, and drinking water contain Al (Yokel and Florence, 2008). In a total diet study in France, Arnich et al. (2012) reported that the main contributors to $\mathrm{Al}$ adult exposure were hot beverages other than coffee (13\%)

* Corresponding author at: Laboratory of Toxicology and Environmental Health, School of Medicine, IISPV, Universitat “Rovira i Virgili”, Sant Llorenç 21, 43201 Reus, Catalonia, Spain.

E-mail address: mariamercedes.gomez@urv.cat (M. Gómez). and vegetables excluding potatoes (11\%). In children, the main contributors were vegetables, excluding potatoes (8\%), pasta (7\%), pastries and cakes (6\%), and dairy-based desserts (6\%). On the other hand, most unprocessed foods contain less than $5 \mathrm{mg} \mathrm{Al} / \mathrm{kg}$, while processed foods such as cake mix or frozen pizza cheese contain around $400 \mathrm{mg} \mathrm{Al} / \mathrm{kg}$ (Yokel, 2013). This high amount of $\mathrm{Al}$ in processed foods is due to the presence of $\mathrm{Al}$ additives used as rising agents, dyes, anti-caking agents and $\mathrm{pH}$ adjusting. One of the most used Al-containing additives is sodium aluminum phosphate (SALP) (Walton, 2012a, 2013). Another potential Al source is the transfer from cookware and utensils into the food (Karbouj et al., 2009.)

Although oral $\mathrm{Al}$ is poorly absorbed, it has been shown that some Al compounds such as maltolate, ascorbate, succinate, lactate or citrate are much more easily absorbed. Specifically, citric acid increases $\mathrm{Al}$ absorption from 5 to 10 times in both humans and animals (Domingo et al., 1993; García et al., 2009; Walton, 2012b; Zhou et al., 2008) and it can easily access to the bloodstream crossing the intestinal mucosa (Domingo et al., 1993; Whitehead et al., 1997; Yokel, 2013). In addition, citric acid is a very common component of human diets and is widely used as food additive (Golub and Keen, 1999; Magaia et al., 2013; Yilmaz et al., 2012). 
Since human Al toxicity is clearly demonstrated, the use of Al compounds has been regulated. In 2007, the Joint Food and Agriculture Organization/World Health Organization Expert Committee on Food Additives (FAO/WHO) reduced the tolerable weekly intake (PTWI) for humans from $7 \mathrm{mg} \mathrm{Al} / \mathrm{kg}$ bw to $1 \mathrm{mg} \mathrm{Al} / \mathrm{kg} \mathrm{bw}$ (Walton, 2012a; WHO, 2007). It is estimated that about one-half of the American population is consuming up to $25 \mathrm{mg} \mathrm{Al}$ per day, while a 5\% may ingest more than $95 \mathrm{mg} \mathrm{Al} /$ day (Greger, 1993; Walton, 2012a). On the other hand, normal human body burden of $\mathrm{Al}$ is $\sim 60 \mathrm{mg}$, but only a $0.25 \%$ reaches the brain. In spite of that relatively low quantity, $\mathrm{Al}$ affects the entorhinal cortex, hippocampus, subiculum, septum, olfactory lobe, piriform cortex, temporal cortex, parietal cortex, frontal cortex, cingulate cortex, amygdala, substantia nigra, basal nucleus of Meynert, dorsal raphe nucleus and locus coeruleus (Walton; 2009, 2012a). These brain regions are particularly vulnerable to deterioration in $\mathrm{AD}$ (Braak and Braak, 1991; Kováks et al., 2001; Walton, 2009, 2012a).

Early onset AD usually has a familial link due to gene mutations, which result in increased secretion of neurotoxic $A \beta$ protein. No specific gene mutations have been associated with sporadic forms of $A D$, which account $85-95 \%$ of $A D$ cases. The lack of identified hereditary links for most $A D$ cases suggests that environmental factors probably interact with other factors to cause the disease. In recent decades, $\mathrm{Al}$ has been suggested as a potential environmental contributor to AD (Walton, 2012a, 2013; Yokel 2013). In vitro and in vivo studies relate Al with the propensity of $A \beta-42$ to form $\beta$ sheets by two ways: the upregulation of gene expression of APP, and the divergence of APP metabolism from its non-amyloidogenic pathway to its amyloidogenic pathway. Both result in the formation of $A \beta$ oligomers, fibrils and plaques (Kawahara et al., 2001; Rodella et al., 2008; Walton, 2012a).

Melatonin (N-acetyl-5-methoxytryptamine) (Mel) is a by-product of serotonin produced mainly by the pineal gland and is one of the main output signals of the central nervous system (Bubenik and Konturek, 2011; Corrales et al., 2013; Mauriz et al., 2013). During the day, the intense light blocks the production of Mel in the pineal gland, while at dusk the blood concentration of pineal-produced Mel begins to increase (Bubenik and Konturek, 2011; Reiter, 1993). This increase of Mel levels provides a signal to all body cells about the onset of night, which is called the daily clock. Similarly, the yearly clock inform from the season using the changes on day length. It is thought that changes on pineal-produced melatonin with aging might also provide the "age clock". From puberty, Mel levels start a steady decline until the old age. This age-dependent decline is controversial since it is not resolved yet whether the Mel changes are the cause, or a consequence of the aging process (Bubenik and Konturek, 2011; Reiter, 1995). In AD patients, profound reduction in Mel secretion and expression of melatonin MT1/MT2 receptor occur. These changes in Mel signaling may contribute to the circadian rhythm alterations and cognitive impairments associated with AD (Baño Otalora et al., 2012).Mel has a strong antioxidant capacity, being able to protect DNA and other macromolecules against free radicals damage (Bubenik and Konturek, 2011; Reiter, 1995; Reiter et al., 2010). Mel also up-regulates the activity of other antioxidants (Corrales et al., 2013; Esparza et al., 2005; García et al., 2009; Gómez et al., 2005; Olcese et al., 2009). Moreover, Mel has antitumoral, immunomodulatory, anti-inflammatory and neuroprotective properties (Baño Otalora et al., 2012; Mauriz et al., 2013) preventing lipid peroxidation and other destructive processes related to oxidative stress (Rodella et al., 2013). A number of investigations have demonstrated the role of Mel in prevention of degenerative disorders in which free radicals generation is involved (i.e., Parkinson's disease and AD) (Antunes Wilhelm et al., 2013; Baño Otalora et al., 2012; Bubenik and Konturek, 2011).
Factors such as the different chemical forms of the Al-administered compound, the doses of both $\mathrm{Al}$ and Mel, the low gastrointestinal $\mathrm{Al}$ absorption, differences in $\mathrm{Al}$ absorption depending on the age, the animal model and the behavioral assessment procedures selected contribute to found a great variability of results (Domingo et al., 1993; García et al., 2009, 2010; Golub, 2001; Walton, 2009). One of the most popular animal models of AD is the APPSWE (Tg2576) transgenic mouse. The main characteristics of this animal model are the overexpression of the $A \beta$ polypeptide gene and the favoring of the cleavage of amyloid polypeptide by the enzyme $\beta$-secretase against $\alpha$-secretase. This leads to an excess of $\beta$ products, which finally deposit and form senile plaques. These deposits begin approximately at 9-12 months of age (Ribes et al., 2008). The behavioral phenotype is characterized by spatial memory deficits after 11-15 months of life, which was shown by altered performance in $\mathrm{Y}$ and Morris water mazes. These behavioral alterations correlate well with the development of amyloid plaques in the frontal, temporal, and entorhinal cortex, as well as in the cerebellum (García et al., 2009; King and Arendash, 2002; Ribes et al., 2008; Zhang et al., 2012).

Based on the above, the main goal of the present study was to evaluate the effects of chronic exposure to Al plus citric acid on spatial learning and memory in wild type and APPSWE transgenic mice, as well as to assess the protective role of Mel administration.

\section{Material and methods}

2.1. Chemicals

Aluminum and citric acid were administered through the diet. Regular chow was supplemented with Al lactate (1 mg of Al per g of chow) (Harlan Ibérica, Barcelona, Spain) (Gómez et al., 2008) and with 3.2\% of citric acid (Sigma Chemical, St. Louis, MO, USA) (Cit) (Golub and Keen, 1999). Mel (Sigma Chemical, St. Louis, MO, USA) was dissolved in absolute ethanol and added to the drinking water to a final ethanol concentration of $0.066 \%$, it was administered in feeding bottles protected from the light. Control drinking water contained also a $0.066 \%$ of ethanol. A fresh Mel solution was prepared twice a week.

\subsection{Animals and treatment}

Adult transgenic (Tg2576) and wild-type mice were used. Parental APPSWE hemizygous male mice were obtained from Taconic Europe (Lille Skensved, Denmark). After a quarantine week, males were backcrossed with female mice (C57BL6/SJL) obtained from Charles River (Barcelona). Because of the aggressive behavior among males, which results in frequent injuries, only females were used in the current study. At 2 months of age, female mice were selected, genotyped using mouse tail, and separated according to the genotype. Mice were housed in an animal room maintained at $22 \pm 2{ }^{\circ} \mathrm{C}$, a relative humidity of $50 \pm 10 \%$, and a 12-h light/dark automatic light cycle (light: $08.00-20.00 \mathrm{~h}$ ). All animals were allowed free access to food and water. The experimental procedures used in the current study were approved by the Ethics Committee of Animal Research, "Universitat Rovira i Virgili" (Tarragona, Catalonia, Spain). They were carried out according to the Spanish Government Guide and the European Community Guide for animal care.

From 3 months of age, mice were fed with one of the three different diets during 14 consecutive months: regular chow, regular chow supplemented with citric acid (3.2\%), and regular chow supplemented with both citric acid (3.2\%) and Al lactate (1 $\mathrm{mg} \mathrm{Al} / \mathrm{g}$ chow). Melatonin-treated animals received also $10 \mathrm{mg} / \mathrm{kg} /$ day of $\mathrm{Mel}$ through drinking water. Animals were divided into the ten following experimental groups: control wild (C-W), control Tg2576 (C-Tg), melatonin wild (Mel-W), melatonin Tg2576 (Mel-Tg), citric acid wild (Cit-W), citric acid Tg2576 (Cit-Tg), aluminum lactate and citric acid wild (AlCit-W), aluminum lactate and citric acid Tg2576 (AlCit-Tg), aluminum lactate and citric acid plus melatonin wild (AlCitMel-W), and aluminum lactate and citric acid plus melatonin Tg2576 (AlCitMel$\mathrm{Tg}$ ). 12-14 animals per group were selected. After 14 months of treatment (17 months of age), behavioral tests were initiated.

\subsection{Behavioral tests}

All mice were evaluated for behavior. General activity was assessed in an openfield, while spatial learning and memory were evaluated in a Morris water maze spatial reference task. 


\subsection{Open-field test}

The open-field apparatus consisted of a wood $60 \mathrm{~cm} \times 60 \mathrm{~cm}$ square field surrounded by a $50 \mathrm{~cm}$ high dark wall. A $10 \mathrm{~cm}$ area near the surrounding wall was delimitated and considered as the periphery. The rest of the open-field (more than $10 \mathrm{~cm}$ far from the wall) was considered as the central area. The distance travelled, the ratio (distance in center/total distance travelled), and the time in the center of the open-field were analyzed as a measure of anxiety-like behavior (Ribes et al., 2008). Mice were allowed to move freely around the open-field and to explore the environment during the test for a total of $15 \mathrm{~min}$.

The path of the animals was recorded by a video camera (Sony CCD-IRIS model), which was placed above the square and connected to a VHS videocassette recorder (Panasonic AG-5700 model). The video tracking program Etho-Vision ${ }^{\circledR}$ from Noldus Information Technologies (Wageningen, The Netherlands) was used to measure the time spent in each area, the total distance traveled as a measure of the horizontal activity, and the number of rearings as a measure of the vertical activity. The open-field apparatus was cleaned after each mouse with $70 \%$ ethanol solution to eliminate any possible odor cues.

\subsection{Morris water maze}

Two days after examining general motor activity, spatial learning was evaluated using the Morris water maze. The maze consisted of a circular tank (diameter: $1 \mathrm{~m}$, height: $0.60 \mathrm{~m}$ ) and an escape platform located $1 \mathrm{~cm}$ below the water surface and at the center of one of the four quadrants of the maze. Extra-maze cues were placed around the pool to provide a spatial configuration of the task. An internal mobile wall within the maze was added to prevent egocentrically learning (García et al., 2009; Ribes et al., 2008). Mice were exposed to one training session per day during 10 days. Each training session consisted of two trials separated by a $60 \mathrm{~s}$ inter-trial period. At the beginning of each trial, the mouse was placed into the pool with its nose pointing toward the wall from one of the four starting positions. The starting positions were randomly varied between trials. The maximum duration of each trial was $90 \mathrm{~s}$. If the animals failed to reach the platform during the fixed period, they were conducted to it by the researcher, remaining there for $30 \mathrm{~s}$.

Retention of the task was assessed by a probe trial on days 3rd, 5th, 8th and 10th of training before the training session to evaluate the short term retention of the task, as well as $72 \mathrm{~h}$ after the last day of training to evaluate the long term retention of the task. The probe trial consisted on $60 \mathrm{~s}$ of free swim without the escape platform. During that period, the time spent and the distance traveled at target quadrant (TGQ) were measured and compared to the chance level (the $15 \mathrm{~s}$ that mice would spend at each quadrant by chance). Times in TGQ exceeding the chance level should show a consistent memory.

Animal performance was recorded by a video camera placed above the maze. Data were analyzed by the video tracking program Etho-Vision ${ }^{\circledR}$. The swim-path length, the latency to find the escape platform during the training sessions, as well as the total time and the percentage of time spent by the mouse swimming in the target quadrant for the probe trial, were measured as indicators of water maze performance. Results from daily trials were averaged for each mouse.

\subsection{Statistics}

All data were analyzed using the software Statistical Package for the Social Sciences SPSS (version 15). Behavioral data were analyzed by means of a four-way ANOVA (genotype $\times$ citrate $\times$ melatonin $\times \mathrm{Al}$ ) and with a four-way ANOVA for repeated measures, using the time as the repeated measure, and genotype and treatment as factors. The homogeneity of the variances was analyzed by the Levene test and a one-way ANOVA followed by a Tukey test for multiple comparisons. If the variances were not homogenous, the non-parametric Kruskal-Wallis test and the Mann-Whitney U-test were used. A probability value $p<0.05$ was considered as statistically significant.

\section{Results}

There were various deaths during the experimental period. In the wild-type animals, no deaths occurred in Cit and AlCit groups, while the mortality in C-W, Mel-W and AlCitMel-W groups was $5.55 \%, 3.33 \%$ and $10 \%$, respectively. However, the mortality in the C-Tg, Cit-Tg, Mel-Tg, AlCit-Tg and AlCitMel-Tg groups was clearly higher: $22 \%, 33 \%, 26.3 \%, 26.3 \%$, and 33\%, respectively. According to the supplier, the percentage of mortality expected in these animals is about $20 \%$, which was here slightly higher.

\subsection{Open-field}

General activity in the open-field throughout the 15 min of testing period was analyzed by a four-way ANOVA (genotype $\times$ aluminum $\times$ citrate $\times$ melatonin) for repeated measures using three 5-min periods as the within-subject factor and the distance traveled as dependent variable. The distance traveled decreased over time indicating habituation to the new space $(F(2$, $148)=7.401, p=0.001)$. An overall effect of the genotype was observed in the total distance traveled $(F(1,148)=48.072$, $p<0.001)$. Tg mice traveled more distance than $\mathrm{W}$ mice Fig. 1 . An overall effect of $\operatorname{Mel}(F(1,148)=15.740, p<0.001)$ and an interaction (genotype $\times$ melatonin) $(F(1,148)=20.974, p<0.001$ ) were also observed in the distance traveled. Mel increased the distance traveled only in Tg mice Fig. 2D, while no effects of Al or Cit were observed. Regarding to the vertical activity, an effect of the genotype $(F(1,148)=4.140, p=0.044)$ as well as interactions (genotype $\mathrm{X}$ aluminum), and (genotype $\times$ citrate) $(F(1,148)=13.711$, $p<0.001 ; F(1,148)=4.381, p=0.039$, respectively) were observed in the number of rearings.

Taking into account the general effect of the genotype and the multiple interactions observed, we separately assessed the differences between groups in W and Tg mice by one-way ANOVA. An effect of the group in the distance traveled was observed in both $\mathrm{W}(F(4,93)=4.941, p=0.001)$ and $\mathrm{Tg}$ mice $(F(4,54)=2.827$, $p=0.036)$. Animals in the Mel-W group traveled less distance than the respective controls Fig. 2A. Post-hoc analysis in Tg mice failed to show differences between groups Fig. 2C. An effect of group was observed in the number of rearings in $\operatorname{Tg}$ mice $(F(4,54)=4.671$, $p=0.003$ ) while animals in the Cit-Tg group showed a higher vertical activity than those in the Mel-Tg and AlCit-Tg groups Fig. 2F.

The activity in the center of the open-field was analyzed to detect anxious-like behaviors. A four-way ANOVA (genotype $\times$ aluminum $\times$ citrate $\times$ melatonin) was performed on the frequency of entries to the center, the ratio (distance traveled in the center/total distance traveled), and the time spent in the center. An overall effect of the genotype was observed in the frequency of entries $(F(1,148)=6.600, p=0.012)$. Tg mice did more entries to the center of the open-field. However, they did not spent more time in the center, or traveled more distance Fig. 3. Mel increased the time that the animals spent in the center $(F(1,148)=10.392, p=0.002)$ independently of the genotype Fig. 4(A and B). No effects of $\mathrm{Al}$ or Cit were observed in the activity in the center.

\subsection{Morris water maze acquisition}

The 10 days of acquisition in the Morris water maze were analyzed by a four-way ANOVA (genotype $\times$ aluminum $\times$ citrate $\times$ melatonin) for repeated measures using the session as

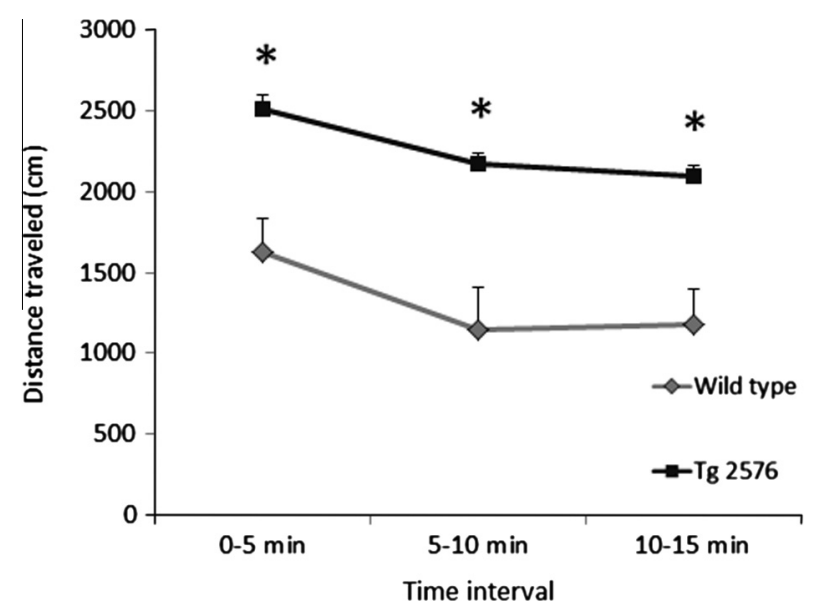

Fig. 1. Distance traveled in an open-field through 15 min of testing in wild type and transgenic mice. An asterisk $\left(^{*}\right)$ indicates significant differences between groups at $p<0.05$. 

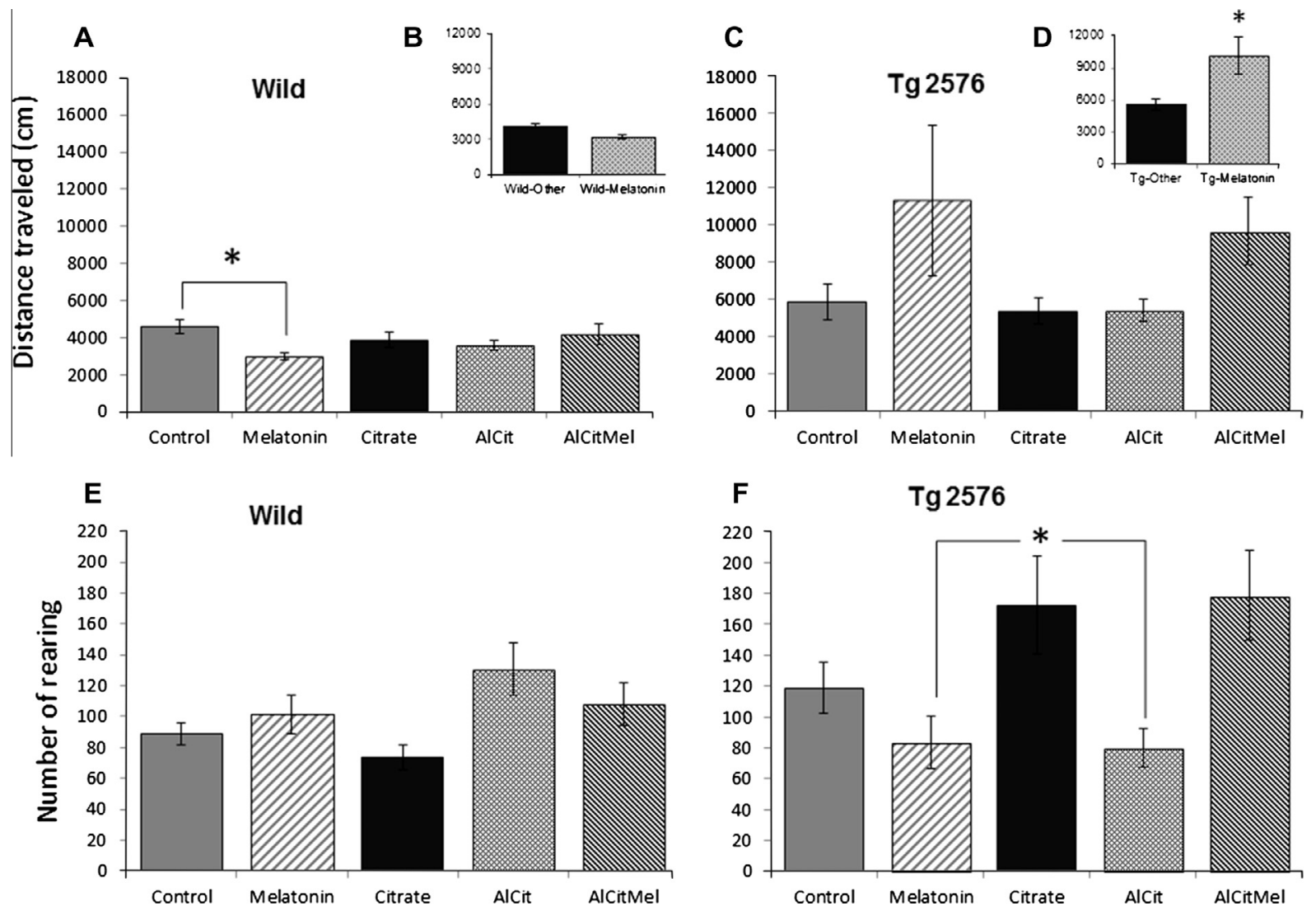

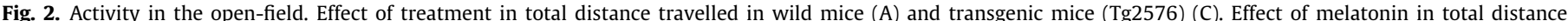

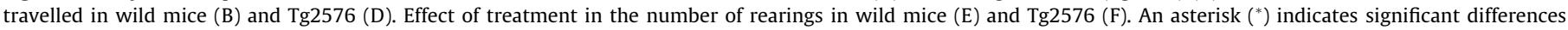
between groups $(p<0.05)$.
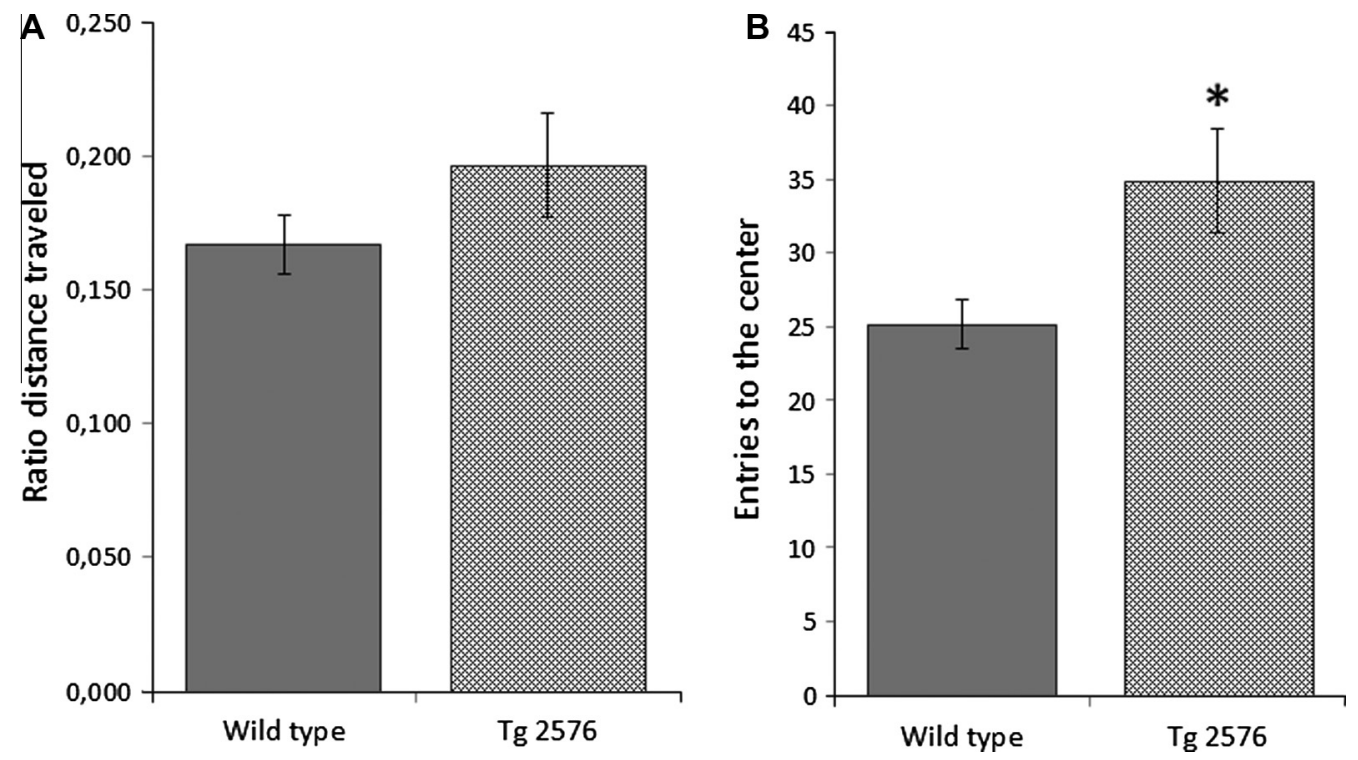

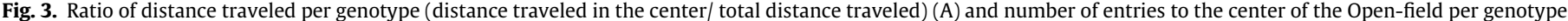
(B). An asterisk $\left(^{*}\right)$ indicates significant differences between groups $(p<0.05)$.

the within-subject factor and the latency and swim distance to the platform as dependent variables. A general improvement in performance was observed with training $(F(9,131)=22.177, p<0.001)$. An overall effect of genotype was noted in both the latency $(F(1$, $131)=34.208, p<0.001)$ and swim distance $(F(1,131)=44.438$, $p<0.001)$. Tg mice showed higher latencies and swam more dis- tance to reach the platform along the 10 acquisition days Fig. 5 . Moreover, an interaction (genotype $\times$ citrate) was observed in both latency and swim distance $(F(1,131)=7.373, p=0.008 ; F(1$, $131)=5.703, p=0.018$ respectively). In turn, an interaction (genotype $\times$ melatonin) was also found in latency and swim distance $(F(1,131)=8.454, p=0.004 ; F(1,131)=9.650, p=0.002$ respec - 


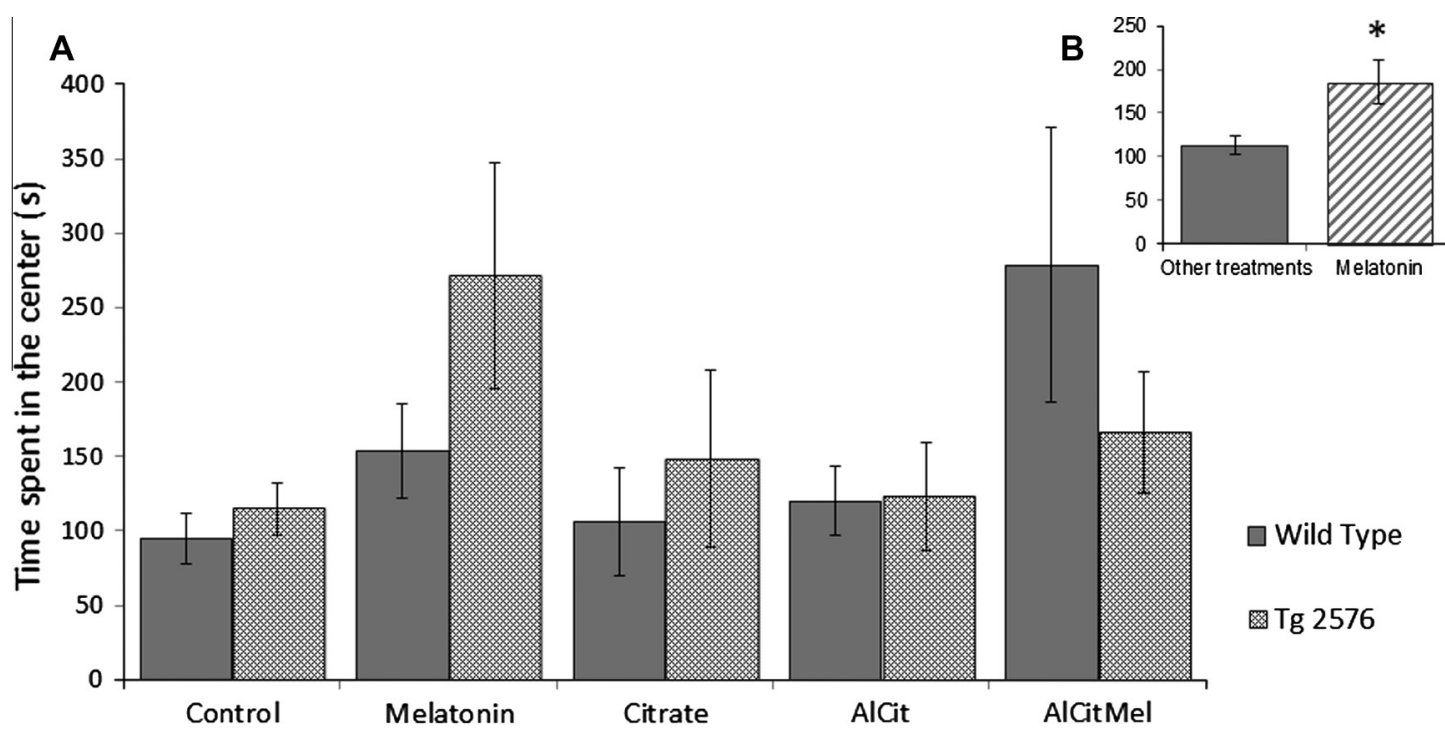

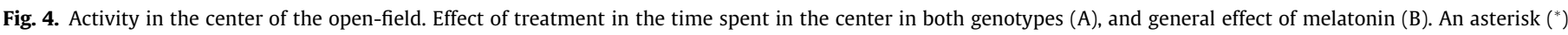
indicates significant differences between groups $(p<0.05)$.

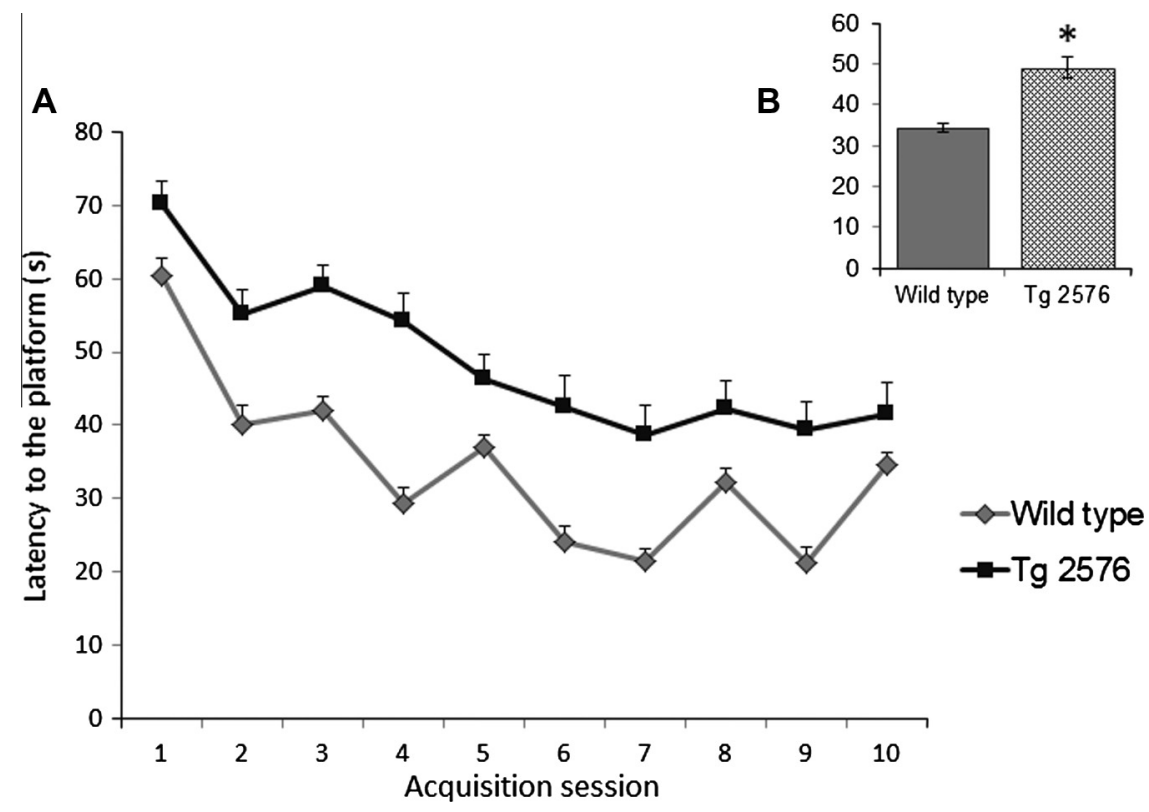

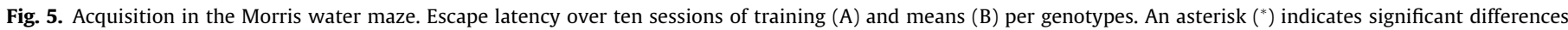
between groups at $p<0.05$.

tively). To better understand these interactions, we analyzed the group effect separately for each genotype. One-way ANOVA showed an effect of group in $\mathrm{Tg}$ mice on latency $(F(4,51)=2.912$, $p=0.031)$ and swim distance $(F(4,51)=3.012, p=0.027)$. AlCit$\mathrm{Tg}$ animals showed the worst performance through all the acquisition Figs. 6 and 7. Post-hoc analyses showed a significant difference between AlCit-Tg and AlCitMel-Tg groups in the distance traveled Fig. 7D. Velocity was affected by the genotype $(F(1,131)=8.742$, $p=0.004)$. Tg animals swam faster than $\mathrm{W}$ mice. Any treatment affected the search velocity.

\subsection{Retention in the Morris water maze during acquisition}

The retention during the training period was analyzed by a four-way ANOVA (genotype $\times$ aluminum $\times$ citrate $\times$ melatonin) for repeated measures, using the session (3rd, 5th, 8th and 10th) as within-subject factor, and the time spent in the target quadrant (TGQ) as dependent variable. A global improvement in retention was observed with training $(F(3,131)=5.907, p=0.001)$, while an interaction (genotype $\times$ melatonin) was found in the time spent in the $\operatorname{TGQ}(F(1,131)=7.892, p=0.006)$.

To better analyze the execution in probe trials we compared the time spent in the TGQ with the chance level $(15 \mathrm{~s})$ by means of a $t$-test in each group. In the 3rd session, only mice in the AlCitMel-Tg group showed retention over the chance level. At the end of the training (10th session), all $\mathrm{W}$ mice excepting those in the AlCitMel-W, group, as well as all Tg mice excepting those in the Mel-Tg and Cit-Tg groups, showed a retention above the chance level. However, the differences were only statistically significant for the Mel-W and Al-Cit-Mel-Tg groups Fig. 8. 

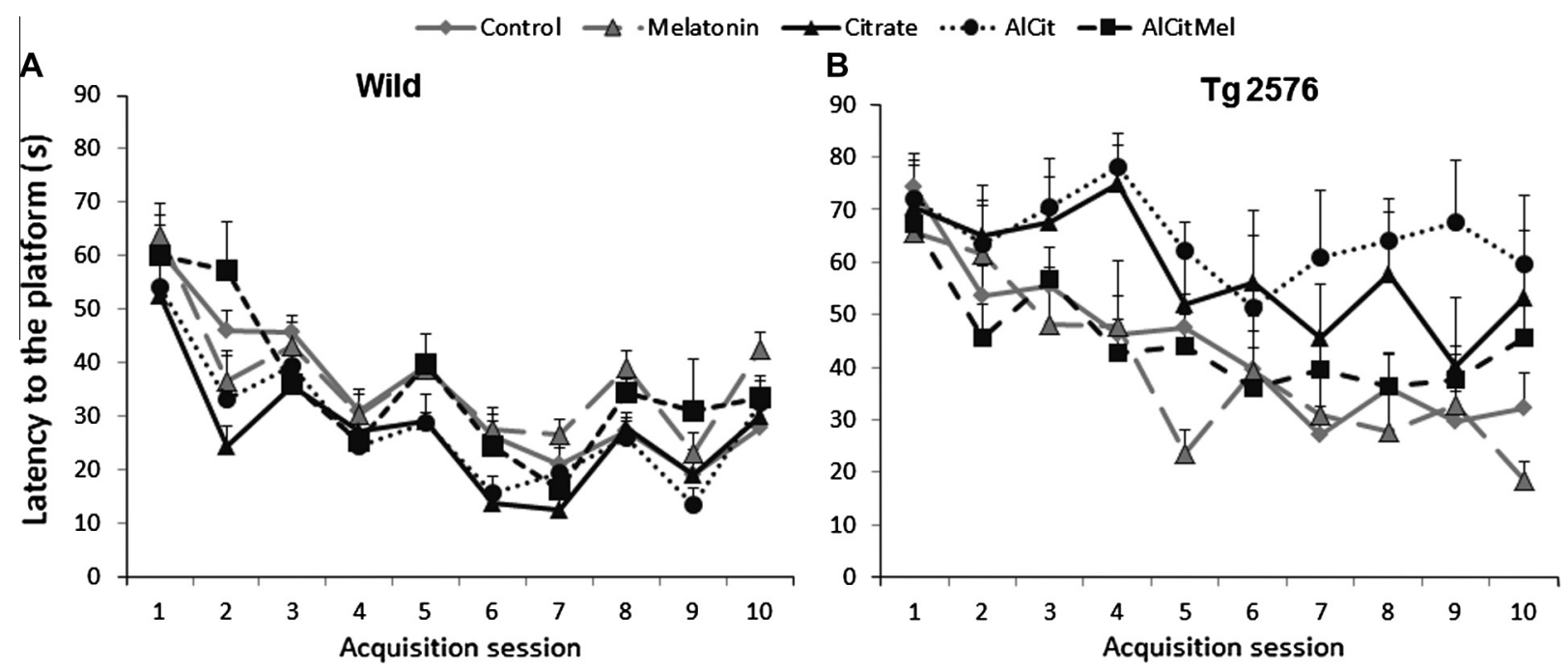

Fig. 6. Acquisition in the Morris water maze. Escape latency over ten sessions of training on wild mice (A) and Tg2576 mice (B).
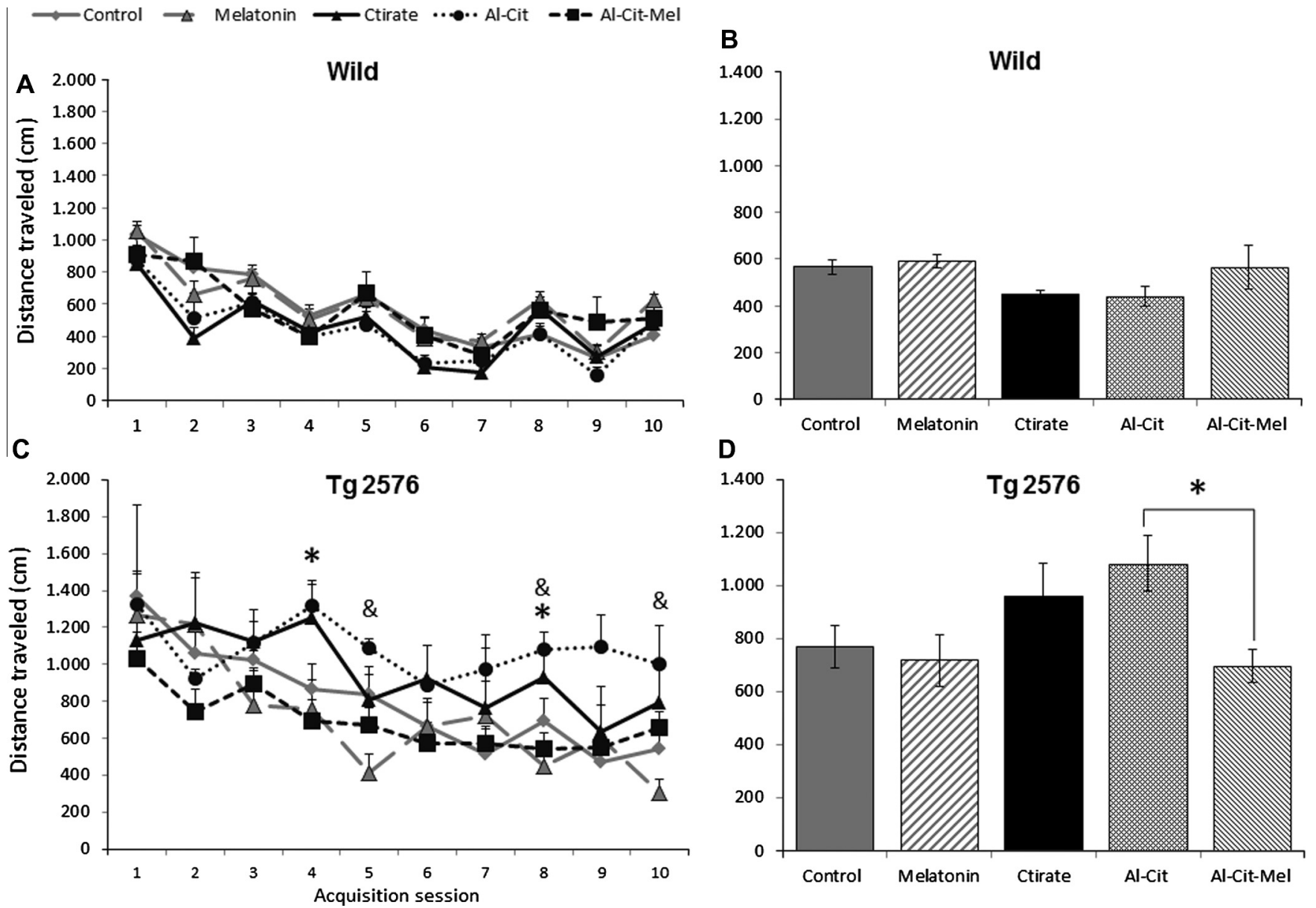

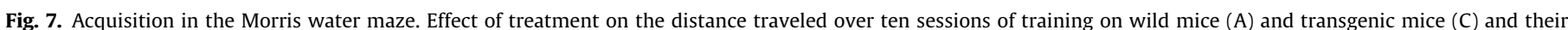

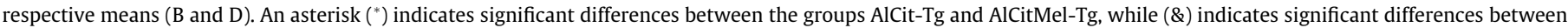
the groups AlCit-Tg and Mel-Tg $(p<0.05)$.

\subsection{Long-term retention in the Morris water maze}

The time spent in the TGQ in the probe trial performed $72 \mathrm{~h}$ after the last training session was analyzed by a four-way ANOVA (genotype $\times$ aluminum $\times$ citrate $\times$ melatonin). An interaction (genotype $\times$ melatonin) was observed $(F(1,125)=8.542, p=$ $0.004)$. To better analyze the execution in long-term retention session, we compared the time spent in the TGQ with the chance level (15 s) by a $t$-test in each group. Only animals in the Control-W and AlCitMel-Tg groups showed a long-term retention Fig. 9. 


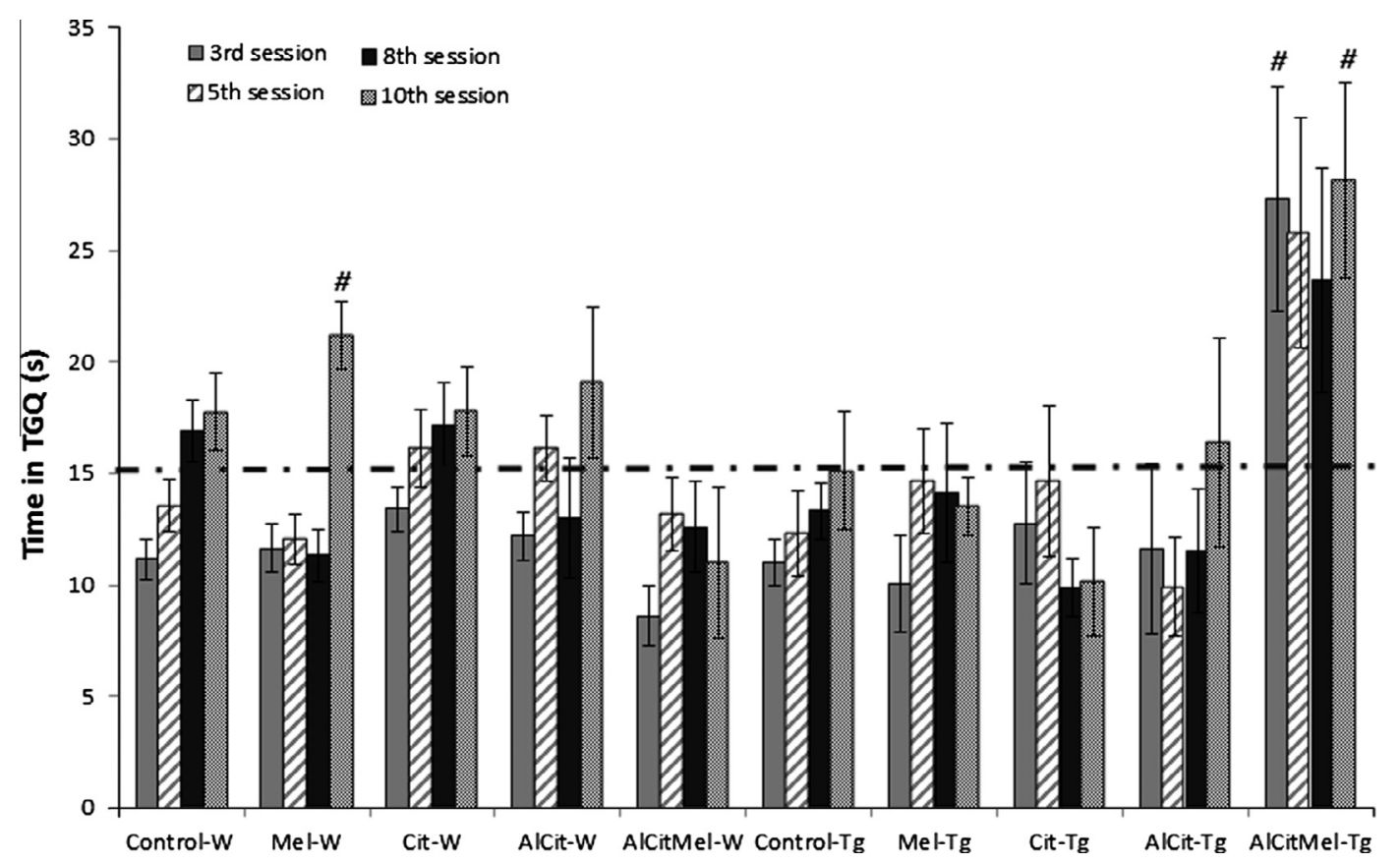

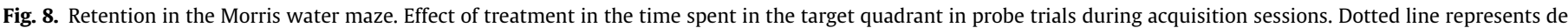
chance level (15 s) and the symbol (\#) indicates a performance significantly different from the chance level within a group at $p<0.05$.

\section{Discussion}

Alzheimer's disease is one of the most prevalent causes of human deterioration in modern society affecting old people. Genetic and environmental factors contribute to the initiation and progression of the disease. Neurotoxins like Al have been also proposed as potential environmental risk factors to develop AD. The increase of the number of commercial and industrial applications of $\mathrm{Al}$ has multiplied the studies, while a link up with $\mathrm{AD}$ and other neuropathological diseases has gained support (Gómez et al., 2008; Praticò et al., 2002; Rodella et al., 2008; Yokel, 2000). The present study tested a dose of $1 \mathrm{mg} \mathrm{Al} / \mathrm{g}$ diet in mice. Considering the daily ingestion of a mouse (3-4 g/day), the quantity administered would be more than 100 times the amount equivalent to the maximum human Al daily intake. In previous studies (García et al., 2009; Gómez et al., 2008), only $307 \mu \mathrm{g} \mathrm{Al} / \mathrm{g}$ were administered instead of $1 \mathrm{mg} / \mathrm{g}$, which was due to a mistake of the supplier.

\subsection{Effects of the genotype}

The genotype influenced both activity in the open-field and learning in the Morris water maze. In the open-field, Tg mice showed a higher general activity. Increased activity in $\mathrm{Tg}$ mice was previously reported (García et al., 2009; King et al., 1999; Lalonde et al., 2003; Ribes et al., 2008). In the current investigation, $\mathrm{Tg}$ mice also showed an increased frequency of entries in the center of the open-field, suggesting a lower anxiety in these animals.
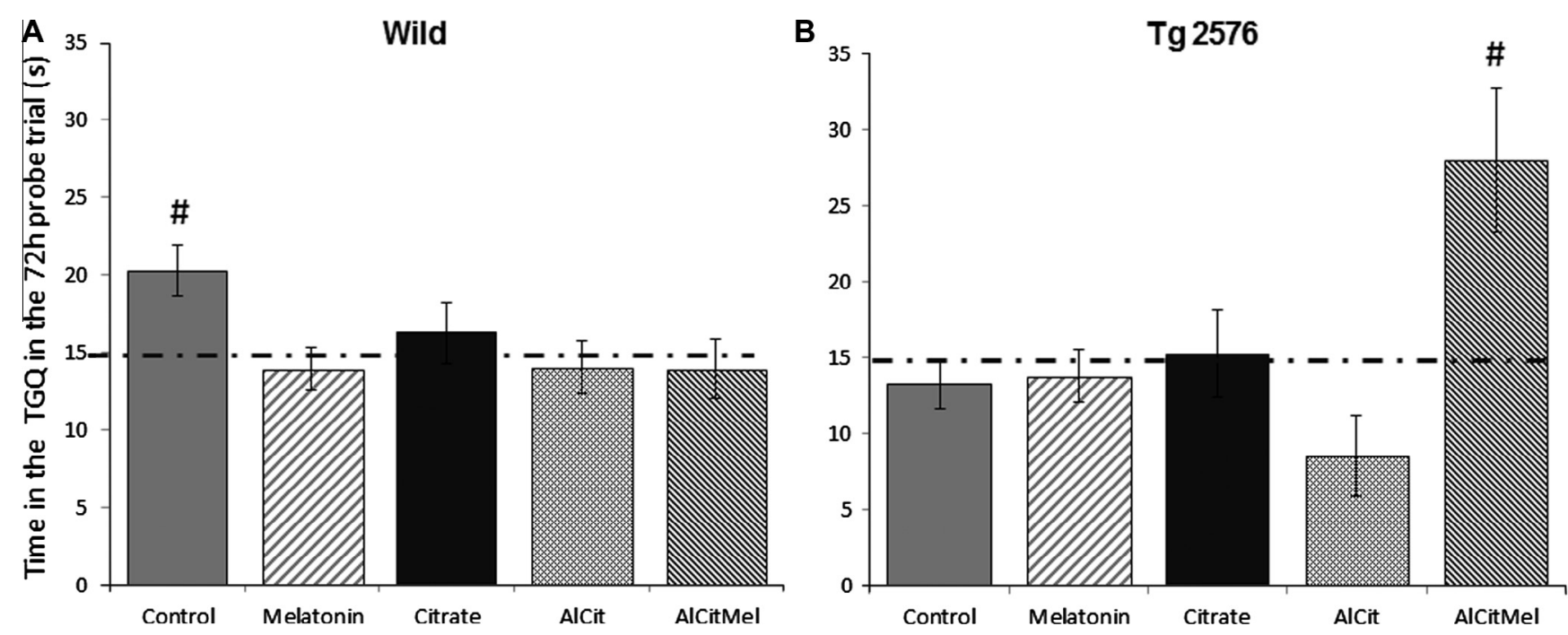

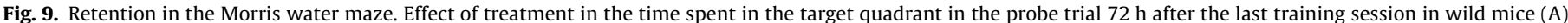

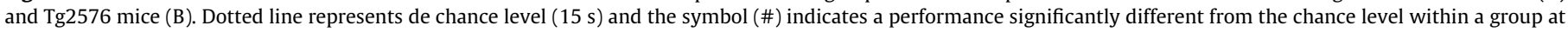
$p<0.05$. 
In relation to this, Lalonde et al. (2003) observed in Tg mice a higher exploration of the open arms in the elevated plus-maze. In the current study, Tg mice did not spent more time in the center. Thus, the increased entries to the center may reflect a higher general activity. Rodgers et al. (2012) reported that overexpression of APP may interfere in the developing process in transgenic rodents inducing long-lasting hyperactivity.

In the Morris water maze, $\mathrm{Tg}$ mice showed worse acquisition than $\mathrm{W}$ mice. The relationship between insoluble $\mathrm{A} \beta$ accumulation and cognitive impairment has been well-established. Learning and memory deficits were reported in rats after intraventricular administration of $A \beta$ fragments in hippocampus (Liu et al., 2013) and also in Tg mice, which show amyloid plaques (Hsiao et al., 1996; Ribes et al., 2008; Westerman et al., 2002). However, some controversy exists related to the age of onset of the deficits in $\mathrm{Tg}$ mice and the discernment between $A \beta$-induced effects, or the deficit triggered by the age itself. On the other hand, some investigations reported only memory deficits in Tg females (King et al., 1999), or failed to find any effect of the genotype (Bizon et al., 2007). Discrepant results might be due to differences in the Morris water maze protocol. Bizon et al. (2007) used a protocol in which visible platform and hidden platform sessions were interleaved. These authors observed that both $\mathrm{W}$ and $\mathrm{Tg}$ mice were using a non-spatial strategy to find the platform. Preventing the use of egocentric learning strategies, diminishing the number of trials per day and controlling intra-maze cues may increase the sensitivity of spatial tests to better detect functional deficits at early states of neurodegeneration (García et al., 2009; Ribes et al., 2008). In the present investigation, an internal mobile wall was added to the Morris water maze and rotated between trials in order to control intra-maze cues, which respond to the need of a learning and memory task with increased demands.

\subsection{Effects of citric acid}

It has been demonstrated that a number of dicarboxylic acids, including citric acid, enhance $\mathrm{Al}$ absorption, by modifying the $\mathrm{pH}$ conditions and favoring the formation of salts with higher solubility (García et al., 2009; Silva et al., 2013; Walton, 2012b; Wu et al., 2012).

Unexpectedly, we noted an effect of citric acid in vertical activity of Tg mice. The Cit-Tg animals showed increased rearings compared to Mel-Tg and AlCit-Tg. Another interaction between citric acid and Tg genotype was observed in the acquisition of the Morris water maze, showing the Cit-Tg and the AlCit-Tg groups similar results. A possible explanation is that the citric acid would have increased the absorption of $\mathrm{Al}$ (and other metals) present in the standard diet and drinking water (Golub and Keen, 1999; Walton, 2012a, 2013; Yokel, 2013; Zhou et al., 2008). The increased absorption of these metals could be the reason of the observed behavioral alterations. However, the effects were subtle and require further investigations.

\subsection{Effects of aluminum and citric acid}

No effects of AlCit were observed on the general activity. In accordance with these results, prolonged $\mathrm{Al}$ exposure during development (Roig et al., 2006) or in adults (Colomina et al., 2002; García et al., 2009; Ribes et al., 2008) did not show to affect activity levels in rodents. Although no general effects of AlCit were observed in the Morris water maze, AlCit-Tg mice showed the worst acquisition of the task among all groups. Accordingly, we previously reported poor performance in the Morris water maze in 11-months $\mathrm{Tg}$ mice after prolonged $\mathrm{Al}$ exposure (García et al., 2009; Ribes et al., 2010). Silva et al. (2013) also found learning deficits in the T-maze after treatment with $\mathrm{Al}$ citrate in rats. In turn, developmental exposure to high doses of $\mathrm{Al}$ also impaired learning in adult mice (Golub and Germann, 2001). In contrast, Al treatment impaired learning in $\mathrm{W}$ mice, but not in $\mathrm{Tg}$ at 9 months of age (Ribes et al., 2008).

In the current study, AlCit-Tg mice did not exhibit long-term retention. Deficits in long term retention were also found in rats exposed to Al citrate Silva et al. (2013). After administering a lower dose of Al, Ribes et al. (2008) found that neither W nor Tg mice remembered the location of the platform. Retention deficits after Al treatment have been also reported by other authors (Jing et al., 2004; Miu et al., 2003).

\subsection{Effects of melatonin}

Mel increased horizontal activity in Tg mice, while $\mathrm{W}$ mice treated with Mel showed lower activity compared to the respective controls. Other studies in similar Tg mouse models did not show any effect of Mel on activity (Corrales et al., 2013; García et al., 2009; Olcese et al., 2009). The age of the animals or the treatment duration, could explain the discrepant results. The treatments in those referenced studies lasted from 4 to 6 months, while in the current investigation the treatment duration was longer (15 months).

Mel increased the time spent in the center in $\mathrm{Tg}$ and $\mathrm{W}$ mice. The anxiolytic effects of Mel have been also reported in previous studies in rodents (Corrales et al., 2013; García et al., 2009; Olcese et al., 2009; Pandi-Perumal et al., 2006). Mel improved learning in AlCit treated $\mathrm{Tg}$ mice. Some recent data indicate that antioxidants such as Mel can reduce hippocampal-dependent memory deficits in Tg2576 mice (García et al., 2009; McKenna et al., 2012; Silva et al., 2013). However, it is important to note that in the current study Mel was able to reverse or to avoid the damage induced by AlCit treatment in $\mathrm{Tg}$ mice, but it did not improve the performance of control Tg group. Accordingly, in a previous investigation we observed a better retention in mice treated with $\mathrm{Al}$ and Mel compared to animals in the Al-treated groups (García et al., 2009). That improved retention of AlCit- treated Tg mice may be a result of the strong antioxidant capacity of Mel, its ability to protect against the free radicals damage, and the Mel up-regulation of the activity of several other antioxidants (Corrales et al., 2013; García et al., 2009; Reiter, 1995; Reiter et al., 2010). Some studies have already shown the possible beneficial role of Mel in prevention of neurodegenerative diseases such as Parkinson's disease and AD (Akbulut et al., 2008; Bubenik and Konturek, 2011; Lack et al., 2001).

In summary, $\mathrm{Tg}$ genotype increased the general activity in the Open-field, worsened the acquisition of the Morris water maze task but did not seem to affect the retention of the task. Neither citric acid nor aluminum plus citric acid treatments affected the general activity. Melatonin treatment increased the general activity in $\mathrm{Tg}$ mice but decreased it on $\mathrm{W}$ mice. Furthermore, an anxiolytic effect of melatonin was noted in both genotypes. In the Morris water maze AlCit-Tg mice showed the worst acquisition and did not showed long term retention of the task. Unexpectedly, Cit-Tg mice showed also a bad acquisition but effects were subtle and require further investigation. Melatonin treatment improved retention on $\mathrm{Tg}$ mice treated with $\mathrm{Al}$.

\section{Conclusions}

Tg mice are more sensitive to the worsening effects of $\mathrm{Al}$ in spatial learning, corroborating the results of previous studies (García et al., 2009; Ribes et al., 2008). Moreover, Mel showed an anxiolytic effect in wild-type and $\mathrm{Tg}$ mice. It is also important to remark that AlCit-Tg mice were not able to remember the task, while 
AlCitMel-Tg did it. This indicates complex interaction between Mel and $\mathrm{Al}$ in $\mathrm{Tg}$ mice, suggesting an stimulatory effect that favors learning and retention, as well as probably a protective effect of Mel.

\section{Conflict of Interest}

The authors declare that there are no conflicts of interest.

\section{Transparency Document}

The Transparency document associated with this article can be found in the online version.

\section{Acknowledgement}

Financial support for this study was provided by "Fondo de Investigación Sanitaria”, Ministry of Health, Spain, through Grant No. PI080065.

\section{References}

Akbulut, K.G., Gonül, B., Akbulut, H., 2008. Exogenous melatonin decreases ageinduced lipid peroxidation in the brain. Brain Res. 1238, 31-35.

Antunes Wilhelm, E., Ricardo Jesse, C., Folharini Bortolatto, C., Wayne Nogueira, C., 2013. Correlations between behavioural and oxidative parameters in a rat quinolinic acid model of Huntington's disease: protective effect of melatonin. Eur. J. Pharmacol. 701, 65-72.

Arnich, N., Sirot, V., Riviere, G., Jean, J., Noel, L., Guerin, T., Leblanc, J.C., 2012. Dietary exposure to trace elements and health risk assessment in the 2nd French Total Diet Study. Food Chem. Toxicol. 50, 2432-2449.

Baño Otalora, B., Popovic, N., Gambini, J., Popovic, M., Viña, J., Bonet-Costa, V., Reiter R.J., Camello, P.J., Rol, M.Á., Madrid, J.A., 2012. Circadian system functionality, hippocampal oxidative stress, and spatial memory in the APPswe/PS1dE9 transgenic model of Alzheimer disease: effects of melatonin or ramelteon. Chronobiol. Int. 29, 822-834.

Bizon, J., Prescott, S., Nicolle, M.M., 2007. Intact spatial learning in adult Tg2576 mice. Neurobiol. Aging. 28, 440-446.

Braak, H., Braak, E., 1991. Neuropathological stageing of Alzheimer-related changes. Acta Neuropathol. 82, 239-259.

Bubenik, G.A., Konturek, S.J., 2011. Melatonin and aging: prospects for human treatment. J. Physiol. Pharmacol. 62, 13-19.

Colomina, M.T., Roig, J.L., Sánchez, D.J., Domingo, J.L., 2002. Influence of age on aluminum-induced neurobehavioral effects and morphological changes in rat brain. Neurotoxicology 23, 775-781.

Corrales, A., Martínez, P., García, S., Vidal, V., García, E., Flórez, J., Sanchez-Barceló, E.J., Martínez-Cué, C., Rueda, N., 2013. Long-term oral administration of melatonin improves spatial learning and memory and protects against cholinergic degeneration in middle-aged Ts65Dn mice, a model of Down syndrome. J. Pineal Res. 54, 346-358.

Domingo, J.L., Gómez, M., Sánchez, D.J., Llobet, J.M., Corbella, J., 1993. Effect of various dietary constituents on gastrointestinal absorption of aluminum from drinking water and diet. Res. Commun. Chem. Pathol. Pharmacol. 79, 377-380.

Esparza, J.L., Gómez, M., Nogués, M.R., Paternain, J.L., Mallol, J., Domingo, J.L., 2005. Melatonin reduces oxidative stress and increases gene expression in the cerebral cortex and cerebellum of aluminum-exposed rats. J. Pineal Res. 39, $129-136$.

Fekete, V., Vandevijvere, S., Bolle, F., Van Loco, J., 2013. Estimation of dietary aluminum exposure of the Belgian adult population: evaluation of contribution of food and kitchenware. Food Chem. Toxicol. 55, 602-608.

García, T., Ribes, D., Colomina, M.T., Cabré, M., Domingo, J.L., Gómez, M., 2009. Evaluation of the protective role of melatonin on the behavioral effects of aluminum in a mouse model of Alzheimer's disease. Toxicology 265, 49-55.

García, T., Esparza, J.L., Nogués, M.R., Romeu, M., Domingo, J.L., Gómez, M., 2010 Oxidative stress status and RNA expression in hippocampus of an animal model of Alzheimer's disease after chronic exposure to aluminum. Hippocampus 20, $218-225$.

Golub, M.S., 2001. Behavioral studies in animals: past and potential contribution to the understanding of the relationship between aluminum and Alzheimer's disease. In: Exley, C. (Ed.), Aluminum and Alzheimer's disease. Elsevier, pp. 169-187.

Golub, M.S., Germann, S.L., 2001. Long-term consequences of developmental exposure to aluminum in a suboptimal diet for growth and behavior of Swiss Webster mice. Neurotoxicol. Teratol. 23, 365-372.

Golub, M.S., Keen, C.L., 1999. Effects of dietary aluminum on pubertal mice. Neurotoxicol. Teratol. 21, 595-602.
Gómez, M., Esparza, J.L., Nogués, M.R., Giralt, M., Cabré, M., Domingo, J.L., 2005. Prooxidant activity of aluminum in the rat hippocampus: gene expression of antioxidant enzymes after melatonin administration. Free Radical Biol. Med. 38, $104-111$.

Gómez, M., Esparza, J.L., Cabré, M., García, T., Domingo, J.L., 2008. Aluminum exposure through the diet: metal levels in AbetaPP transgenic mice a model for Alzheimer's disease. Toxicology 249, 214-219.

Greger, J.L., 1993. Aluminum metabolism. Annu. Rev. Nutr. 13, 43-63.

Hsiao, K., Chapman, P., Nilsen, S., Eckman, C., Harigaya, Y., Younkin, S., Yang, F., Cole, G., 1996. Correlative memory deficits Abeta elevation and amyloid plaques in transgenic mice. Science 274, 99-102.

Jing, Y., Wang, Z., Song, Y., 2004. Quantitative study of aluminum-induced changes in synaptic ultrastructure in rats. Synapse 52, 292-298.

Karbouj, R., Desloges, I., Nortier, P., 2009. A simple pre-treatment of aluminium cookware to minimize aluminium transfer to food. Food Chem. Toxicol. 47, 571-577.

Kawahara, M., Kato, M., Kuroda, Y., 2001. Effects of aluminum on the neurotoxicity of primary cultured neurons and on the aggregation of beta-amyloid protein. Brain Res. Bull. 55, 211-217.

King, D.L., Arendash, G.W., 2002. Behavioral characterization of the Tg2576 transgenic model of Alzheimer's disease through 19 months. Physiol. Behav. $75,627-642$.

King, D.L., Arendash, G.W., Crawford, F., Sterk, T., Menendez, J., Mullan, M.J., 1999. Progressive and gender-dependent cognitive impairment in the APP (SW) transgenic mouse model for Alzheimer's disease. Behav. Brain Res. 103, 145162.

Kováks, T., Cairns, N.J., Lantos, P.L., 2001. Olfactory centres in Alzheimer's disease: olfactory bulb is involved in early Braak's stages. NeuroReport 12, 285-288.

Lack, B., Daya, S., Nyokong, T., 2001. Interaction of serotonin and melatonin with sodium, potassium, calcium, lithium and aluminum. J. Pineal Res. 31, 102-108.

Lalonde, R., Lewis, T.L., Strazielle, C., Kim, H., Fukuchi, K., 2003. Transgenic mice expressing the betaAPP695SWE mutation: effects on exploratory activity anxiety and motor coordination. Brain Res. 977, 38-45.

Liu, X.J., Yuan, L., Yang, D., Han, W.N., Li, Q.S., Yang, W., Liu, Q.S., Qi, J.S., 2013. Melatonin protects against amyloid- $\beta$-Induced impairments of hippocampal LTP and spatial learning in rats. Synapse 67, 626-636.

Magaia, T., Uamusse, A., Sjöholm, I., Skog, K., 2013. Dietary fiber, organic acids and minerals in selected wild edible fruits of Mozambique. SpringerPlus 2, 88.

Mauriz, J.L., Collado, P.S., Veneroso, C., Reiter, R.J., González-Gallego, J., 2013. A review of the molecular aspects of melatonin's anti-inflammatory actions: recent insights and new perspectives. J. Pineal Res. 54, 1-14.

McKenna, J.T., Christie, M.A., Jeffrey, B.A., McCoy, J.G., Lee, E., Connolly, N.P., Ward, C.P., Strecker, R.E., 2012. Chronic ramelteon treatment in a mouse model of Alzheimer's disease. Arch. Ital. Biol. 150, 5-14.

Miu, A.C., Andreescu, C.E., Vasiu, R., Olteanu, A.I., 2003. A behavioral and histological study of the effects of long-term exposure of adult rats to aluminum. Int. J. Neurosci. 113, 1197-1211.

Olcese, J.M., Cao, C., Mori, T., Mamcarz, M.B., Maxwell, A., Runfeldt, M.J., Wang, L., Zhang, C., Lin, X., Zhang, G., Arendash, G.W., 2009. Protection against cognitive deficits and markers of neurodegeneration by long-term oral administration of melatonin in a transgenic model of Alzheimer disease. J. Pineal Res. 47, 82-96.

Pandi-Perumal, S.R., Srinivasan, V., Maestroni, G.J., Cardinali, D.P., Poeggeler, B., Hardeland, R., 2006. Melatonin. Nature's most versatile biological signal? FEBS J. 273, 2813-2838.

Percy, M.E., Kruck, T.P., Pogue, A.I., Lukiw, W.J., 2011. Towards the prevention of potential aluminum toxic effects and an effective treatment for Alzheimer's disease. J. Inorg. Biochem. 105, 1505-1512.

Praticò, D., Uryu, K., Sung, S., Tang, S., Trojanowski, J.Q., Lee, V.M., 2002. Aluminum modulates brain amyloidosis through oxidative stress in APP transgenic mice. FASEB J. 16, 1138-1140.

Reiter, R.J., 1993. The melatonin rhythm: both a clock and a calendar. Experientia 49, 654-664.

Reiter, R.J., 1995. The pineal gland and melatonin in relation to aging: a summary of the theories and of the data. Exp. Gerontol. 30, 199-212.

Reiter, R.J., Tan, D.X., Fuentes-Broto, L., 2010. Melatonin: a multitasking molecule. Prog. Brain Res. 181, 127-151.

Ribes, D., Colomina, M.T., Vicens, P., Domingo, J.L., 2008. Effects of oral aluminum exposure on behavior and neurogenesis in a transgenic mouse model of Alzheimer's disease. Exp. Neurol. 214, 293-300.

Ribes, D., Colomina, M.T., Vicens, P., Domingo, J.L., 2010. Impaired spatial learning and unaltered neurogenesis in a transgenic model of Alzheimer's disease after oral aluminum exposure. Curr. Alzheimer Res. 7, 401-408.

Rodella, L.F., Ricci, F., Borsani, E., 2008. Aluminium exposure induces Alzheimer's disease-like histopathological alterations in mouse brain. Histol. Histopathol. 23, 433-439.

Rodella, L.F., Favero, G., Rossini, C., Foglio, E., Bonomini, F., Reiter, R.J., Rezzani, R. 2013. Aging and vascular dysfunction: beneficial melatonin effects. Age (Dordr) 35, 103-115.

Rodgers, S.P., Born, H.A., Das, P., Jankowsky, J.L., 2012. Transgenic APP expression during postnatal development causes persistent locomotor hyperactivity in the adult. Mol Neurodegener 18, 7-28.

Roig, J.L., Fuentes, S., Colomina, M.T., Vicens, P., Domingo, J.L., 2006. Aluminum restraint stress and aging: behavioral effects in rats after 1 and 2 years of aluminum exposure. Toxicology 218, 112-124. 
Silva, A.F., Aguiar, M.S., Carvalho, O.S., Santana, L.N., Franco, E.C., Lima, R.R., Siqueira, N.V., Faro, L.R., Gomes-Leal, W., 2013. Hippocampal neuronal loss decreased GFAP immunoreactivity and cognitive impairment following experimental intoxication of rats with aluminum citrate. Brain Res. 1491, 23-33.

Walton, J.R., 2009. Functional impairment in aged rats chronically exposed to human range dietary aluminum equivalents. Neurotoxicology 30, 182-193.

Walton, J.R., 2012a. Cognitive deterioration and associated pathology induced by chronic low-level aluminum ingestion in a translational rat model provides an explanation of Alzheimer's disease, tests for susceptibility and avenues for treatment. Int. J. Alzheimers Dis. 2012, 914947. http://dx.doi.org/10.1155/2012/ 914947.

Walton, J.R., 2012b. Evidence that ingested aluminum additives contained in processed foods and alum-treated drinking water are a major risk factor for Alzheimer's disease. Curr. Inorg. Chem. 2, 19-39.

Walton, J.R., 2013. Aluminum involvement in the progression of Alzheimer's disease. J. Alzheimers Dis. 35, 7-43.

Westerman, M.A., Cooper-Blacketer, D., Mariash, A., Kotilinek, L., Kawarabayashi, T. Younkin, L.H., Carlson, G.A., Younkin, S.G., Ashe, K.H., 2002. The relationship between Abeta and memory in the Tg2576 mouse model of Alzheimer's disease. J. Neurosci. 22, 1858-1867.

Whitehead, M.W., Farrar, G., Christie, G.L., Blair, J.A., Thompson, R.P., Powell, J.J., 1997. Mechanisms of aluminum absorption in rats. Am. J. Clin. Nutr. 65, 1446-1452.

World Health Organization, 1989. Aluminium in: 657. Aluminium (WHO Food Additive Series 24), <http://www.inchem.org/documents/jecfa/jecmono/ v024je07.htm>.
World Health Organization, 2007. Evaluation of certain food additives and contaminants in Sixty-seventh report of the joint FAO/WHO Expert Committee on Food Additives. WHO Technical Report Series <http:// www.who.int/ipcs/publications/jecfa/reports/trs940.pdf>.

Wu, X., Li, J., Hu, J.N., Deng, Z.Y., 2012. The effects of glutamate and citrate on absorption and distribution of aluminum in rats. Biol. Trace Elem. Res. 14, 83-90.

Yilmaz, S., Unal, F., Yüzbasioglu, D., Celik, M., 2012. DNA damage in human lymphocytes exposed to four food additives in vitro. Toxicol. Ind. Health PMID: 23188648 .

Yokel, R.A., 2000. The toxicology of aluminum in the brain: a review. Neurotoxicology 21, 813-828.

Yokel, R.A., 2013. Aluminum. In: Caballero, B. (Ed.), Encyclopedia of Human Nutrition, third ed. Elsevier, pp. 57-63, http://dx.doi.org/10.1016/B978-0-12375083-9.00008-8.

Yokel, R.A., Florence, R.L., 2008. Aluminum bioavailability from tea infusion. Food Chem. Toxicol. 46, 3659-3663.

Yumoto, S., Kakimi, S., Ohsaki, A., Ishikawa, A., 2009. Demonstration of aluminum in amyloid fibers in the cores of senile plaques in the brains of patients with Alzheimer's disease. J. Inorg. Biochem. 103, 1579-1584.

Zhang, Q.L., Jia, L., Jiao, X., Guo, W.L., Ji, J.W., Yang, H.L., Niu, Q., 2012. APP/PS1 transgenic mice treated with aluminum: an update of Alzheimer's disease model. Int. J. Immunopathol. Pharmacol. 25, 49-58.

Zhou, Y., Harris, W.R., Yokel, R.A., 2008. The influence of citrate, maltolate and fluoride on the gastrointestinal absorption of aluminum at a drinking water-relevant concentration: a 26Al and 14C study. J. Inorg. Biochem. 102, 798-808. 